\title{
Russian homophones and visual word recognition
}

\author{
Daria Chernova
}

Laboratory for Cognitive Studies, Saint Petersburg State University, Russia

https://doi.org/10.36505/ExLing-2019/10/0012/000374

\begin{abstract}
Our study focuses on visual word processing in silent reading for comprehension. We compare the processing of homophone errors and non-homophonous orthographic neighbours with processing of target words in congruent sentential context. We find that homophone errors are the most costly in processing as they provoke the competition between the phonological and visual representation of the word.
\end{abstract}

Key words: silent reading, phonological representation, orthographic representation, homophones

\section{Introduction}

The role of phonology in visual word recognition is a crucial theoretical issue in psycholinguistics research of reading (Clifton 2015).

The main question is what is stored in mental lexicon - phonological representations mapped onto semantics or both phonological and orthographic ones?

The dual-route model (Coltheart 1980) argues for two independent ways of printed words processing; one relies on phonological representation and the other on the visual image of the word. For frequent words processed by skilled readers, the visual route to the meaning is accessed faster (Jared et al. 1999).

The single-route theory (Frost 1998) claims that phonological processing is a default procedure of cognitive system and meaning only can be accessed via phonological representation. Strong phonological models claim phonological processing to be mandatory and automatized.

Homophones can be a suitable material for testing these theories (Van Orden 1987, Newman et al.2012): if a homophone is processed in the same way as any other orthographic neighbour, it gives evidence for the visual route to meaning. If homophony facilitates processing, it gives evidence for the phonological route.

\section{Materials and design}

Most studies on visual processing of homophones have been carried out on English. We address to Russian language, which has more transparent orthography and regular homophony - for example, words with voiced and devoiced consonants in the end (e.g. kot / kot/ 'cat'- kod / kot/ 'code'), which differ by one letter as other orthographic neighbours do.

ExLing 2019: Proceedings of $10^{\text {th }}$ International Conference of Experimental Linguistics, 25-27 September 2019, Lisbon, Portugal 
We constructed three types of stimuli: a correct target word congruent with the context (a), a target word substituted with a homophone (b), and a target word substituted with a non-homophonous orthographic neighbor, i.e. a spelling control (c).

a. Pushistyj kot svernulsia klubkom v kresle.

'The fluffy cat curled up in the armchair'.

b. Pushistyj kod svernulsia klubkom v kresle .

'The fluffy code curled up in the armchair'.

c. Pushistyj kol svernulsia klubkom v kresle

'The fluffy stake curled up in the armchair'.

All sentences had 6 words and the target word was always the second one. The materials consisted of 24 sets of target sentences $(8$ sentences for each condition) and 60 filler sentences which contained no errors. The sentences were distributed into three experimental lists according to Latin square design.

\section{Method and participants}

39 native speakers of Russian aged 18-32 performed a word-by-word noncumulative self-paced-reading task and answered comprehension questions after $30 \%$ of sentences. The experiment was run online using Ibex Farm platform.

\section{Results}

We analyzed participants' question-answering accuracy and reading times. The raw reading times (per word) that exceeded $1500 \mathrm{~ms}$ were adjusted to this threshold (about 3\% of the data). As for question-answering accuracy, no participant made more than 5 mistakes, so all subjects were included in the analysis.

No significant differences were found in the processing time of the target word (region 2) in all of the conditions. However, on the word which follows the target one (region 3) t-test shows significant difference between conditions: reaction time for the non-homophonous orthographic neighbour

is significantly longer in comparison to the correct word $(\mathrm{t}=3.5, \mathrm{p}=0002)$, whereas the reaction time for the homophone is the longer in comparison to the orthographic neighbor $(\mathrm{t}=2.9, \mathrm{p}=0.001)$ as well as to the control condition $(\mathrm{t}=3.1, \mathrm{p}=0.0009)$. Thus, homophone is the most costly in processing despite the fact its phonological representation coincides with the contextually consistent word. These differences reveal as spill-over effects as soon as they have to do with contextual integration process.

As for the wrap-up effect, the last word in correct sentences in processed faster in comparison to the last word in sentences containing both types of errors. 
The time course of sentence processing in three conditions is shown in Figure 1.

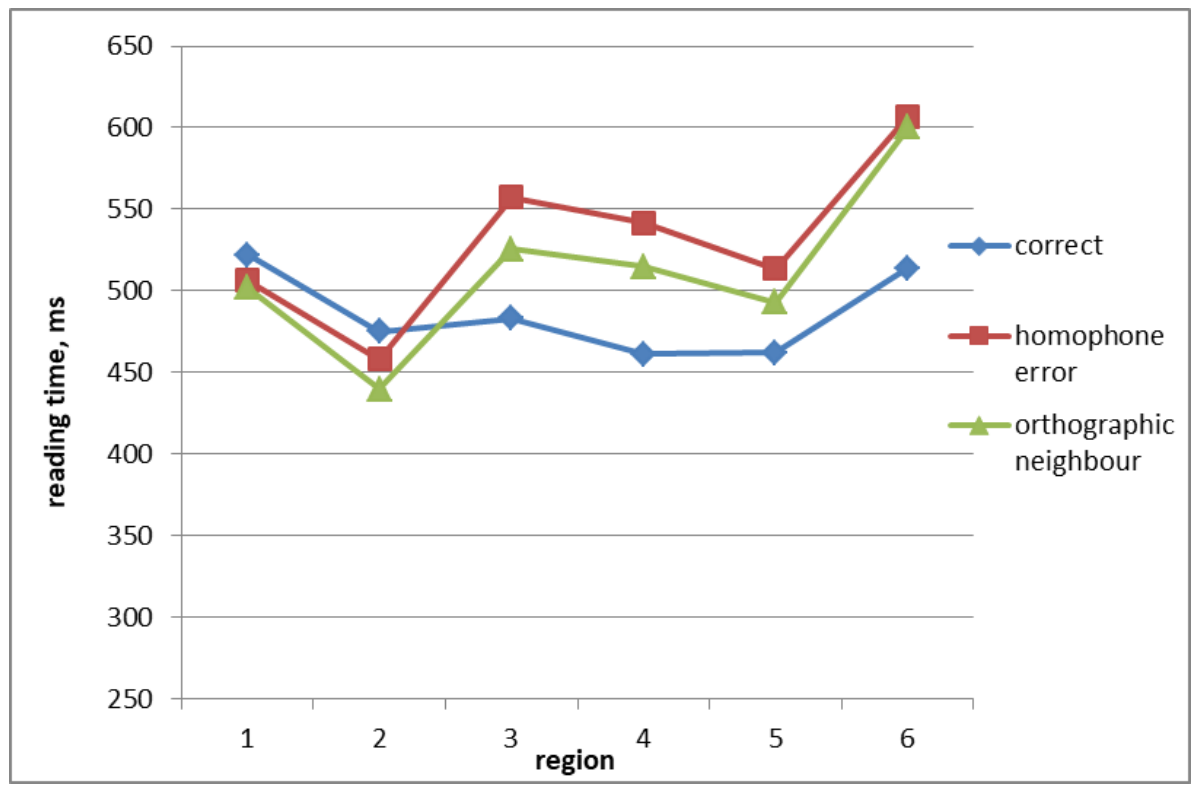

Figure 1. Time course of sentence processing in three conditions

\section{Discussion}

Our data is compatible with dual-route model. Orthographic neighbour instead of the target word slows down the processing due to context inconsistency. As for the homophone, it provokes the competition between phonological and visual representation of the word. Phonological representation activates both the consistent and the inconsistent meaning while visual representation activates the inconsistent one. The competition between the meanings makes the processing even more costly than processing of the inconsistent orthographic neighbor. Thus, homophony rather impedes than facilitates visual word processing.

\section{Acknowledgements}

The reported study was funded by RFBR according to the research project № 18-000646 (18-00-00640).

\section{References}

Clifton, C. 2015. The Roles of Phonology in Silent Reading: A Selective Review. In: Frazier L., Gibson E. (eds) Explicit and Implicit Prosody in Sentence Processing. Studies in Theoretical Psycholinguistics, vol 46. Springer. 
Coltheart, M. 1980. Reading phonological receding and deep dyslexia. In M. Coltheart, K. Patterson, J.C. Marshal (eds.), Deep dyslexia (pp. 197-226). London: Routledge \& K. Paul.

Frost, R. 1998. Toward a strong phonological theory of visual word recognition: True issues and false trails. Psychological Bulletin, 123, 71-99.

Jared, D., O’Donnell, K. 2017. Skilled adult readers activate the meanings of high frequency words using phonology: Evidence from eye tracking. Memory \& Cognition. 43. 334-346.

Newman R.L., Jared D., Haigh C.A. 2012. Does phonology play a role when skilled readers read high-frequency words? Evidence from ERPs. Language and Cognitive Processes, 27:9, 1361-1384.

Van Orden, G.C. 1987. A ROWS is a ROSE: Spelling, sound, and reading. Memory \& Cognition, 15, 181-198. 